Article

\title{
Chemical Modification of Pullulan Exopolysaccharide by Grafting Poly(3-hydroxybutyrate-co-3-hydroxyvalerate) (PHBHV) via Click Chemistry
}

\author{
Layde T. de Carvalho ${ }^{1}$ (D), Maria Luiza da S. Paula ${ }^{1}$, Rodolfo M. de Moraes ${ }^{1}$, Gizelda M. Alves ${ }^{1}$, \\ Talita M. Lacerda ${ }^{2}$, Julio C. dos Santos ${ }^{2}$, Amilton M. dos Santos ${ }^{1}$ and Simone de F. Medeiros ${ }^{1 \text {,* }}$ \\ 1 Department of Chemical Engineering, Engineering School of Lorena, University of São Paulo, EEL-USP, \\ Lorena 12602-810, SP, Brazil; laydetcarvalho@gmail.com (L.T.d.C.); maria.luiza.paula@usp.br (M.L.d.S.P.); \\ rodolfommoraes@hotmail.com (R.M.d.M.); gizelda@dequi.eel.usp.br (G.M.A.); amsantos@usp.br (A.M.d.S.) \\ 2 Department of Biotechnology, Engineering School of Lorena, University of São Paulo, Lorena 12602-810, \\ SP, Brazil; talitalacerda@usp.br (T.M.L.); jsant2000@usp.br (J.C.d.S.) \\ * Correspondence: simonemedeiros@usp.br
}

Received: 23 June 2020; Accepted: 6 August 2020; Published: 29 October 2020

check for updates

\begin{abstract}
Biodegradable and biocompatible copolymers have been often studied for the development of biomaterials for drug delivery systems. In this context, this work reports the synthesis and characterization of a novel pullulan-g-poly(3-hydroxybutyrate-co-3-hydroxyvalerate) (Pull-g-PHBHV) graft copolymer using click chemistry. Well-defined and functional pullulan backbones containing azide groups (PullN $\mathrm{N}_{3}$ ) previously prepared by our group were successfully used for this purpose and propargyl-terminated poly(3-hydroxybutyrate-co-3-hydroxyvalerate) was prepared via transesterification using propargyl alcohol as a chain transfer agent. By an alkyne-azide cycloaddition reaction catalyzed by copper $(\mathrm{Cu}(\mathrm{I}))(\mathrm{CuAAC})$, the graft copolymer Pull- $g$-PHBHV was obtained. The chemical structures of the polymers were accessed by ${ }^{1} \mathrm{H}$ NMR and ${ }^{13} \mathrm{C}$ NMR FTIR. Disappearance of the bands referring to the main bonds evidenced success in the grafting reaction. Besides that, DRX, DSC and TGA were used in order to access the changes in crystallinity and thermal behavior of the material. The remaining crystallinity of the Pull-g-PHBHV structure evidences the presence of PHBHV. Pull-g-PHBHV presented lower degradation maximum temperature values than the starting materials, indicating its minor thermal stability. Finally, the synthesized material is an innovative biopolymer, which has never been reported in the previous literature. It is a bio-derived and biodegradable polymer, chemically modified, resulting in interesting properties which can be useful for their further applications as biomedical systems for controlled delivery, for example.
\end{abstract}

Keywords: pullulan; PHBHV; graft copolymers; polysaccharide; chemical modification

\section{Introduction}

Polymers from renewable sources are interesting materials due to their unique properties and wide applications. In the biomedical area, surgical sutures, tissue engineering and therapeutic agent delivery devices are typical uses for this technology [1,2]. However, due to the limitation in finding all the required properties in a single homopolymer or polymeric family, it is usual to find the combination of different macromolecules in order to obtain a suitable material for a specific request [3-5]. Besides that, polymer modification stands out for creating materials capable of forming important structures such as nanogels, hydrogels and micelles, impacting on the requirements of nanocarrier systems [6]. Amongst the bio-based polymers, polysaccharides and poly(hydroxyalkanoates) are biodegradable and biocompatible materials which are becoming progressively more important despite their relatively early stage of development and commercialization [7]. 
Pullulan is a polysaccharide produced by a yeast-like fungus Aureobasidium pullulans, composed of maltotriose units connected by $\alpha-(1-6)$ linkages [8]. In the human body, pullulan can degrade without activating the immunologic system $[9,10]$. Therefore, its biocompatibility, non-toxicity, biodegradable, hydrophilic and nonionic characteristics contribute to various researches for biomedical applications such as drug and gene delivery, tissue engineering and drug-controlled activation systems. [11,12]. However, this polysaccharide is not self-assembled in aqueous solution due to its high solubility in water [13]. Thus, aiming its application to controlled drug delivery systems, a partial modification of pullulan with hydrophobic materials is necessary, which can result in amphiphilic properties, allowing to obtain self-assembled nanoparticles for delivering drugs [14,15].

Chemical modification helps in combining specific characteristics of different polymers, resulting in a unique material with interesting properties [3]. A modified polysaccharide is often required in order to combine the advantages of a natural polymer with other substances, obtaining a single material with interesting solubility, biodegradability, thermal and mechanical stability [16-18]. Using homogeneous chemical modification, different groups of functions can react with the hydroxyl groups present in the backbone of polysaccharides by esterification, etherification, nucleophilic displacement and graft reactions, resulting in a specific structure such as an amphiphilic material $[19,20]$. Amphiphilic polysaccharide derivatives are advantageous materials that could self-assemble into nanoparticles in an aqueous solution, avoiding the use of organic solvents and providing the encapsulation and release control of drugs [21,22].

Poly(3-hydroxybutyrate-co-3-hydroxyvalerate) (PHBHV) is a biodegradable, biocompatible, non-toxic, hydrophobic material produced from renewable sources by the bacterium Ralstonia eutropha [23,24]. This biopolymer belongs to the poly(hydroxyalkanoates) (PHAs) family, that corresponds to aliphatic poly-esters produced by a variety of microorganisms as intracellular carbon and energy reserve materials [25]. The advantage of PHBHV over biopolymers is the encapsulation time for anticancer drugs as an effective barrier that protects the drug from premature degradation [26]. Besides that, it has been intensively reported as an important biomaterial for biomedical devices in tissue engineering developments and controlled release drug delivery systems, mainly because of two reasons: its great potential for obtaining micro and nanocarriers for drug delivery and its low production costs [27,28].

In the present study, we report the preparation of chemically modified pullulan by grafting poly(3-hydroxybutyrate-co-3-hydroxyvalerate) onto its backbone. The developed grafted copolymers demonstrated a great potential for drug encapsulation systems. The copolymer was prepared via a 1,3-dipolar alkyne-azide cycloaddition reaction, also known as a click chemistry reaction, catalyzed by copper $(\mathrm{Cu}(\mathrm{I}))$. Propargyl-terminated-PHBHV was synthesized by transesterification using propargyl alcohol as a chain transfer agent. Afterwards, it was grafted onto the azide-functionalized pullulan PullN $_{3}$ previously synthesized by our group [29]. The final grafted copolymer demonstrated to be a promising biodegradable and biocompatible material for drug delivery systems, which combine pullulan and PHBHV characteristics, enhancing their physicochemical properties. Furthermore, the copolymer Pull-g-PHBHV is an innovative biopolymer synthesized by the versatile method, click chemistry, a process that has never been reported in the previous literature.

\section{Materials and Methods}

\subsection{Materials}

Figure 1 presents the chemical structure of PullN $_{3}$ used in this work, with a degree of substitution of DS $=0.08$, previously prepared and characterized as described in our last publication [29]. Poly(3-hydroxybutyrate-co-3-hydroxyvalerate) (PHBHV, 8.6\% mol HV, produced by controlled fermentation process using microorganisms) with an average numerical molar mass $(\mathrm{Mn})$ of $159,710 \mathrm{Da}$ and dispersion ( $Ð$ ) equal to 2.86, was purchased by Sigma-Aldrich (St. Louis, MO, USA). Tin dibutyl dilaurate (DBTB, 95\%, Sigma-Aldrich, São Paulo, Brazil), copper bromide (CuBr, 98\%, Sigma-Aldrich), $N, N, N^{\prime}, N^{\prime \prime}, N^{\prime \prime}$-pentamethyldiethylentriamine (PMDTA, 99\%, Sigma-Aldrich), propargyl alcohol 
(99\%, Sigma -Aldrich), deuterated dimethyl sulfoxide (DMSO-d6, 99.9\%, Sigma-Aldrich) and deuterated chloroform $\left(\mathrm{CDCl}_{3}, 99.8 \%\right.$, Sigma-Aldrich) were used as received. Toluene (P.A., Labsynth, São Paulo Brazil) was distilled at atmospheric pressure in the presence of calcium hydride $\left(\mathrm{CaH}_{2}\right)$. $\mathrm{N}, \mathrm{N}$-dimethylformamide (DMF, 99.8\%, Labsynth) was distilled under reduced pressure in the presence of calcium hydride $\left(\mathrm{CaH}_{2}\right)$, and the water used in the entire process was distilled and deionized. Other solvents used in the polymer purification steps, such as, ethyl alcohol (P.A., Labsynth), methyl alcohol (P.A., Labsynth) and ethyl ether (P.A., Labsynth), were used without any prior purification.

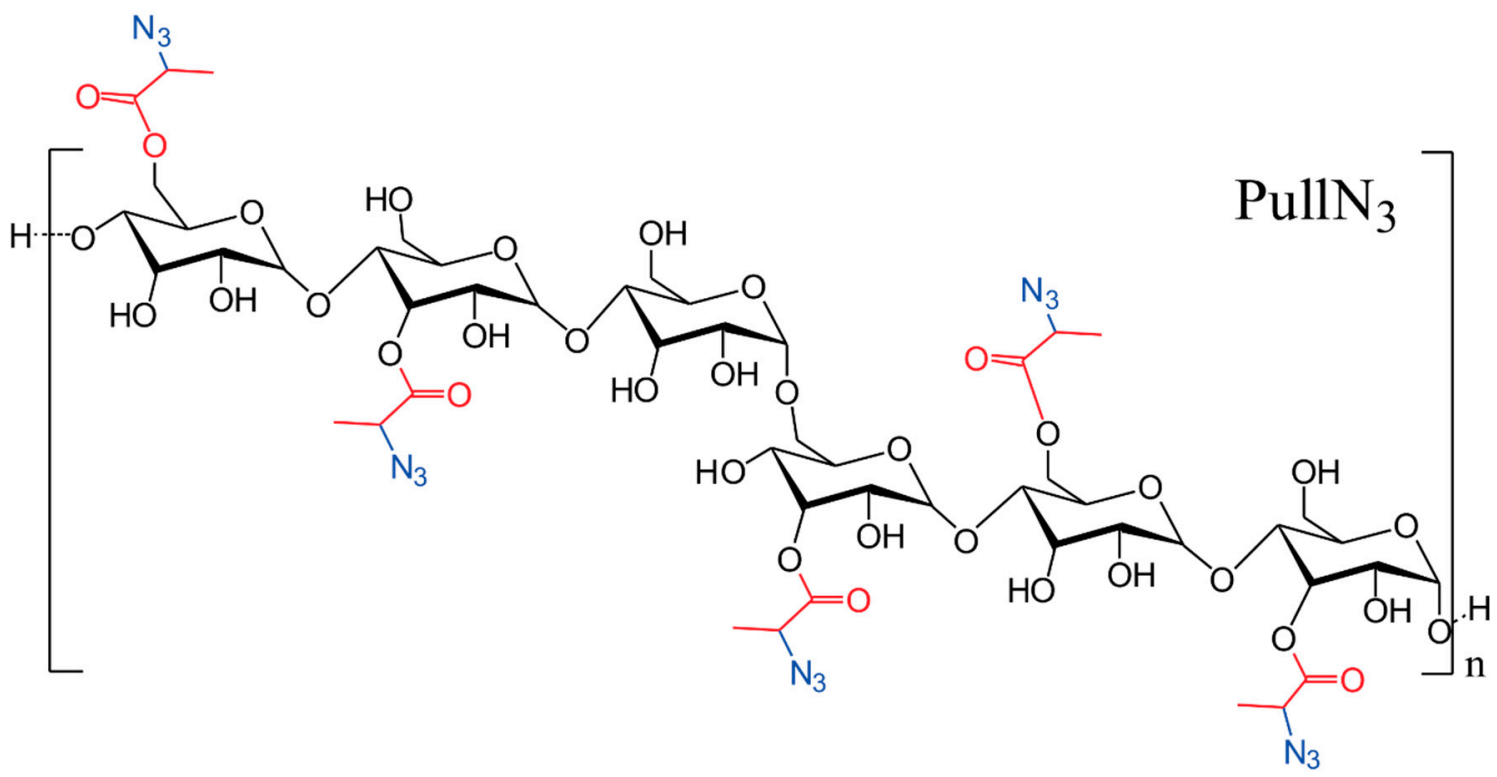

Figure 1. Chemical structure of PullN $N_{3}$ used in this work.

\subsection{Synthesis of Propargyl-Terminated Poly(hydroxybutyrate-co-hydroxyvalerate)}

For the propargyl-terminated PHBHV, the methodology used was adapted from Lemechko et al., 2012 [30] (Scheme 1). Amounts of $20 \mathrm{~g}$ PHBHV (0.125 mmol) and $21.2 \mathrm{~mL}$ propargyl alcohol $(0.367 \mathrm{~mol})$ were mixed with $270 \mathrm{~mL}$ toluene in a round-bottom flask. The mixture was submitted under nitrogen atmosphere and stirred until its complete solubilization. It was then submersed in a glycerin bath at $110{ }^{\circ} \mathrm{C}$, and $1 \mathrm{~g}$ solution of dibutyltin dilaurate $(1.5 \mathrm{mmol})$ was added in $30 \mathrm{~mL}$ toluene, starting the transesterification reaction. After $12 \mathrm{~h}$, the system was cooled and precipitated in cold $\mathrm{n}$-hexane and kept for $24 \mathrm{~h}$ at $0{ }^{\circ} \mathrm{C}$. A white precipitate was obtained by filtration and vacuum-drying.

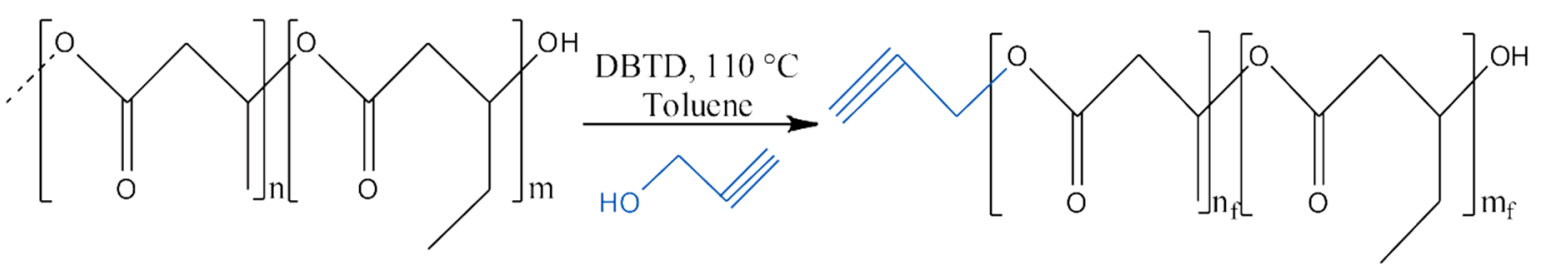

Scheme 1. Synthesis of propargyl-terminated PHBHV via transesterification.

\subsection{Synthesis of Pull-g-PHBHV Grafted Copolymer}

The grafting of PHBHV-alkyne onto the $\mathrm{PullN}_{3}$ backbone was obtained via a 1,3-dipolar cycloaddition reaction between azide and alkyne, using a $\mathrm{Cu}$ (I) catalyst, as shown in Scheme 2. 


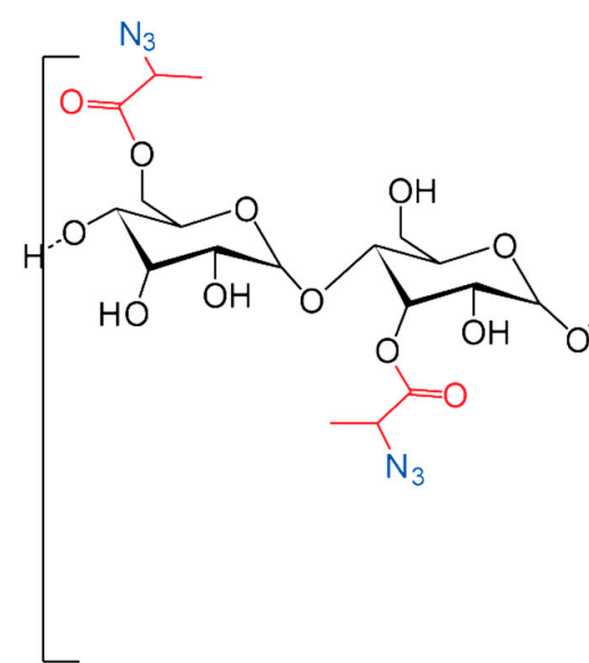<smiles>C=CC(C)(C)OC(=O)C(C)C(C)(OC(=O)C(CC)C(C)(O)C(=O)O)C(C)C</smiles>

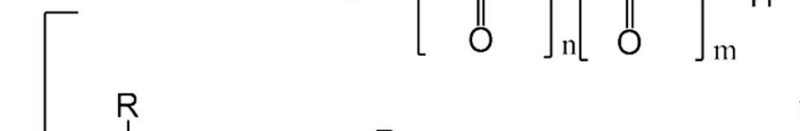<smiles>CC(N)C(=O)OC1OC(O)C(O)C(OC2OC(CO)C(O)C(O)C2O)C1O</smiles>

DMF

$\mathrm{CuBr}$ PMDTA $60^{\circ} \mathrm{C}$ $120 \mathrm{~h}$ $\mathrm{PullN}_{3}$

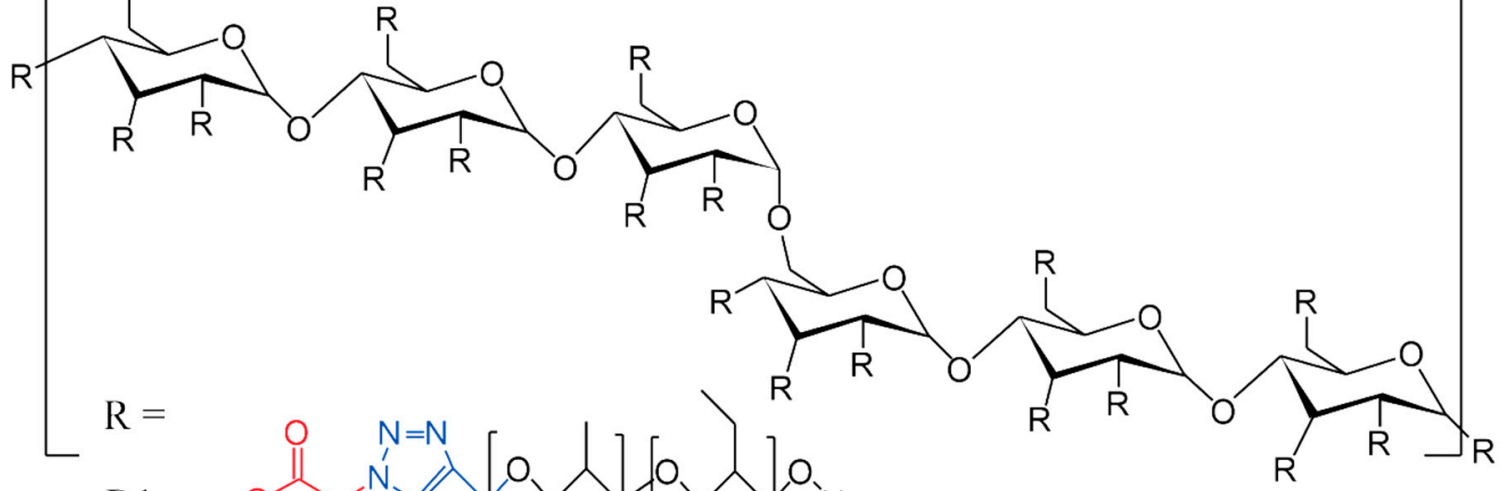

or<smiles>[R]C#COC(=O)C(C)N</smiles>

or

$\mathrm{R} 3=\cdots \mathrm{OH}$

Scheme 2. Cycloaddition reaction between azide-functionalized pullulan (PullN $\mathrm{N}_{3}$ ) and propargyl-terminated poly(hydroxybutyrate-co-hydroxyvalerate).

Initially, $0.0803 \mathrm{~g} \mathrm{PullN}_{3}$ (0.039 mmol of azide units) was added in a round-bottom flask with $0.1593 \mathrm{~g}$ PHBHV-alkyne $(0.039 \mathrm{mmol})$ and $8 \mathrm{~mL}$ DMF. After complete dissolution, under nitrogen atmosphere and vigorous stirring, $2.5 \mathrm{~mL}$ PMDTA solution (171.4 $\mathrm{mg} \cdot \mathrm{mL}^{-1}$ PMDTA in DMF) and $2.5 \mathrm{~mL} \mathrm{CuBr}$ solution $\left(141.88 \mathrm{mg} \cdot \mathrm{mL}^{-1} \mathrm{CuBr}\right.$ in DMF) were added to the system. The flask was sealed and the reaction mixture was stirred for $120 \mathrm{~h}$ at $60^{\circ} \mathrm{C}$. The reaction mixture was precipitated in ethanol, just after finishing the reaction time. The precipitate was filtrated and solubilized again in DMF, which was dialyzed against distilled water for 3 days and lyophilized. 


\subsection{Characterizations}

\subsubsection{Proton Nuclear Magnetic Resonance ( ${ }^{1} \mathrm{H}$ NMR)}

The chemical structures of the modified PHBHV were assessed by proton nuclear magnetic resonance $\left({ }^{1} \mathrm{H}\right.$ NMR) on a Mercury VX 300 spectrometer (Varian, Palo Alto, CA, USA) operating at $300 \mathrm{MHz}$. The solvents used were DMSO- $\mathrm{d}_{6}$ and $\mathrm{CDCl}_{3}$, according to the specific solubility of each polymer.

\subsubsection{Carbon-13 Nuclear Magnetic Resonance $\left({ }^{13} \mathrm{C}\right.$ NMR $)$}

${ }^{13} \mathrm{C}$ solid-state NMR analysis was performed on a Varian Inova spectrometer (Varian, Palo Alto, CA, USA), with frequencies of ${ }^{13} \mathrm{C}$ at $100.5 \mathrm{MHz}$, with the objective of accessing the chemical structure of the grafted copolymer Pull-g-PHBHV, as well as comparing with PullN3 and PHBHV-alkyne. The measurements were taken using a $7 \mathrm{~mm}$ Jackobsen probe with double resonance and a magic rotation angle. All experiments were performed with a rotation of $10 \mathrm{kHz}$ around the magic angle, with contact times for cross-polarization of $1 \mathrm{~ms}$ and time of $5 \mathrm{~s}$ between acquisitions.

\subsubsection{Gel Permeation Chromatography (GPC)}

The numbers of average molecular weight $(\mathrm{Mn})$ and dispersity $(\nexists)$ of the unmodified PHBHV and the propargyl-terminated PHBHV were determined by gel permeation chromatography (GPC), using a Breeze (Waters GPC, USA) chromatograph equipped with a 2414 refractive index (RI) detector. Chloroform with $0.3 \% \mathrm{v} / \mathrm{v}$ of triethylamine was used as the eluent. The sample was prepared with a concentration of $10 \mathrm{mg} \cdot \mathrm{mL}^{-1}$, filtered on a modified polyvinylidene difluoride (PVDF) membrane filter $(0.45 \mu \mathrm{m})$ and subsequently injected into the equipment. Solvent flow rate was $1 \mathrm{~mL} \cdot \mathrm{min}^{-1}$, and the internal temperature of the columns was $30^{\circ} \mathrm{C}$. Calibration curves were obtained using monodispersed polystyrene standards.

\subsubsection{FTIR}

The Fourier transform infrared technique was used to identify the polymer organic functions by a qualitative assessment from a Spectrum 100 FTIR (PerkinElmer, Waltham, MA, USA) equipped with an attenuated total reflection accessory (ATR). Diamond crystal was used as the internal reflection element, and resolution of the analysis was $4 \mathrm{~cm}^{-1}$.

\subsubsection{Thermal Analysis}

Thermal properties of the copolymers were evaluated using thermogravimetric analysis (TGA) and differential scanning calorimetry (DSC). The DSC measurements were performed with TA Instruments' (USA) Q20 equipment. The samples were heated in a rate of $10^{\circ} \mathrm{C} \cdot \mathrm{min}^{-1}$, from -80 to $200{ }^{\circ} \mathrm{C}$ under nitrogen atmosphere. Thermograms were obtained by the second heating cycle in order to eliminate the influence of water in the samples. TGA was performed on the STA 449 F3 Jupiter Netzsch equipment. About 12 to $15 \mathrm{mg}$ of the samples was weighed and submitted to heating from 30 to $700^{\circ} \mathrm{C}$, with heating rates of $10^{\circ} \mathrm{C} \cdot \mathrm{min}^{-1}$, under nitrogen atmosphere.

\subsubsection{X-ray Diffraction}

X-ray diffraction patterns were obtained by a PAN-analytical Empyrean ACMS 101 (Malvern, UK) diffractometer at room temperature. The X-ray tube consisted of a target material made of copper $(\mathrm{Cu})$, which emits $\mathrm{K} \alpha$ radiation. Analyses were performed using a $40 \mathrm{kV}$ accelerating potential and current of $40 \mathrm{~mA}$. Experiments were conducted with a scan range from 10 to $60^{\circ}(2 \theta)$, a step size of $0.02^{\circ}(2 \theta)$ and a counting time of 50 s per step. 


\section{Results and Discussion}

\subsection{Propargyl-Terminated Poly(3-hydroxybutyrate-co-3-hydroxyvalerate)}

The ${ }^{1} \mathrm{H}$ NMR spectra of propargyl alcohol, unmodified PHBHV and PHBHV-alkyne are shown in Figure 2a-c, respectively, while molar masses and dispersity $(\bigoplus)$ of the unmodified PHBHV and PHBHV-alkyne are listed in Table 1 . The ${ }^{1} \mathrm{H}$ NMR spectrum shown in Figure $2 \mathrm{a}$ is characteristic of a propargyl group in accordance with the literature [31,32], exhibiting resonances (ppm) at chemical shifts $4.25\left(2 \mathrm{H}, \mathrm{HC} \equiv \mathrm{C}-\mathrm{CH}_{2-}\right.$, represent by "a") and $2.47\left(1 \mathrm{H}, \underline{\mathrm{HC}} \equiv \mathrm{C}-\mathrm{CH}_{2}-\right.$, represented by " $\left.\mathrm{b}^{\prime \prime}\right)$. In Figure $2 b$, the ${ }^{1} \mathrm{H}$ NMR spectrum shows resonances from 5.20 to $5.28(1 \mathrm{H},-\mathrm{CH}-$ of $\mathrm{HB}$ and $\mathrm{HV}$ unities, represented by " $\mathrm{d}$ " and " $\mathrm{d}$ " ", respectively), from 2.42 to $2.66\left(2 \mathrm{H},-\mathrm{CH}_{2}\right.$ - of $\mathrm{HB}$ and $\mathrm{HV}$ unities, represented by " $c$ " and " $\mathrm{c}$ " ", respectively), $1.64\left(2 \mathrm{H},-\mathrm{CHCH}_{2} \mathrm{CH}_{3}\right.$ of $\mathrm{HV}$, represented by "e" $), 1.26(3 \mathrm{H}$, $-\mathrm{CHCH}_{3}$ of $\mathrm{HB}$, represented by " $\mathrm{g}$ ") and $0.88\left(3 \mathrm{H},-\mathrm{CHCH}_{2} \overline{\mathrm{CH}}_{3}\right.$ of $\mathrm{HV}$, represented by " $\left.\mathrm{f}^{\prime \prime}\right)$, all referring to the protons of the main polymer chain before its transesterification [33]. When compared to the spectrum presented in Figure 2c, the characteristic resonances of PHBHV are observed, but the presence of the proton from the propargyl alcohol molecule bonded at the end of the PHBHV chain at chemical shift $4.68\left(2 \mathrm{H}, \mathrm{HC} \equiv \mathrm{C}-\mathrm{CH}_{2}^{-}\right.$, represented by " $\left.\mathrm{b}^{\prime}\right)$, which is absent in the spectrum shown in Figure $2 \mathrm{~b}$, corroborates the $\mathrm{PHB} \overline{\mathrm{HV}}$ functionalization with alkyne groups.

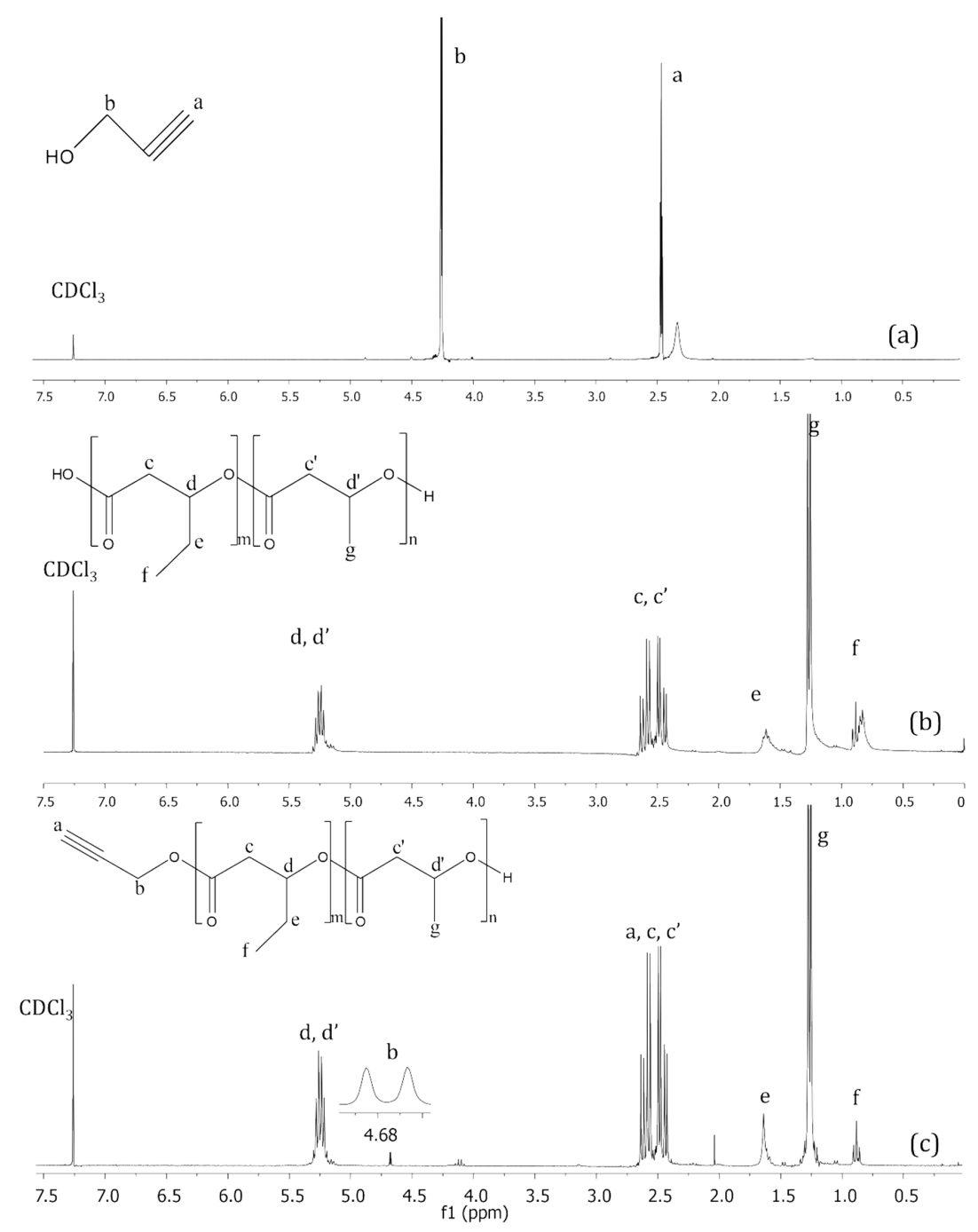

Figure 2. $300 \mathrm{MHz}{ }^{1} \mathrm{HNMR}$ spectra of propargyl alcohol (a), unmodified PHBHV (b) and PHBHV-alkyne after transesterification with propargyl alcohol (c) in $\mathrm{CDCl}_{3}$. 
Table 1. Number average molar masses $(M n)$ and dispersity $(Ð)$ of unmodified PHBHV and PHBHV-alkyne.

\begin{tabular}{cccc}
\hline Sample & $\boldsymbol{M}_{\boldsymbol{n}} \mathbf{( D a}^{\mathbf{a}}$ & $\boldsymbol{M}_{\boldsymbol{n}}(\mathrm{Da})^{\mathbf{b}}$ & $\boldsymbol{D}$ \\
\hline Unmodified PHBHV & - & 114,873 & 2.86 \\
PHBHV-alkyne & 2843 & 4049 & 1.54 \\
\hline
\end{tabular}

Determined by ${ }^{\mathrm{a} 1} \mathrm{H}$ NMR and ${ }^{\mathrm{b}}$ GPC.

Data shown in Table 1 provide evidence about the success of the PHBHV transesterification reaction in the presence of propargyl alcohol. The molar mass was determined by two different methods, GPC and ${ }^{1} \mathrm{H}$ NMR, resulting, respectively, in 4049 and $2843 \mathrm{Da}$. The main reason for the difference between the values is due to the polystyrene standard used in the GPC analysis, which does not have the same hydrodynamic volume in THF. In order to calculate the molar mass of the PHBHV-alkyne, an integration value of 1.00 was attributed to the ${ }^{1} \mathrm{H}$ NMR signal at $4.68 \mathrm{ppm}$ (Figure 2c) from the propargyl unit. After, the signals at 0.88 and $1.26 \mathrm{ppm}$ (represented by " $\mathrm{f}$ " and " $\mathrm{g}$ " in Figure 2c) were integrated, resulting in 4.61 and 43.28 , respectively. This integration values were proportionally multiplied to the molecular weight of the respective monomer, summing up after it. Then, the molecular weight of the propargyl unit was added to the previous calculation, referring to the propargyl group present at the end of the polymer chain. Analyzing the GPC results, it can be notice that the $M n$ value of PHBHV-alkyne reduced significantly from 114,873 to $4049 \mathrm{Da}$, when compared with the data from unmodified PHBHV. In addition, the decreased dispersity $(\nexists)$ from 2.86 to 1.54 demonstrated the homogeneity of the copolymer chains after transesterification. Thus, it is expected that these interesting results represent the potential application of PHBVH-alkyne for future biomedical applications.

The FTIR spectra of unmodified PHBHV and alkyne-functionalized PHBHV (PHBHV-alkyne) have both presented stretching at $1722 \mathrm{~cm}^{-1}$ related to carbonyl groups of the PHBHV. The bands at 2976 and $2929 \mathrm{~cm}^{-1}$, present in both spectra, are characteristic of the asymmetric and symmetric stretching of the $\mathrm{C}-\mathrm{H}$ bonds, respectively. The asymmetric stretching of the $\mathrm{CC}(=\mathrm{O}) \mathrm{O}$ ester group of PHBHV is characterized by the band at $1278 \mathrm{~cm}^{-1}$. The band at $3263 \mathrm{~cm}^{-1}$, present only in the spectrum shown in Figure $3 b$, is characteristic of the axial stretching of the $\mathrm{H}-\mathrm{C} \equiv$ bond and therefore characterizes the PHBHV functionalization with alkyne groups.

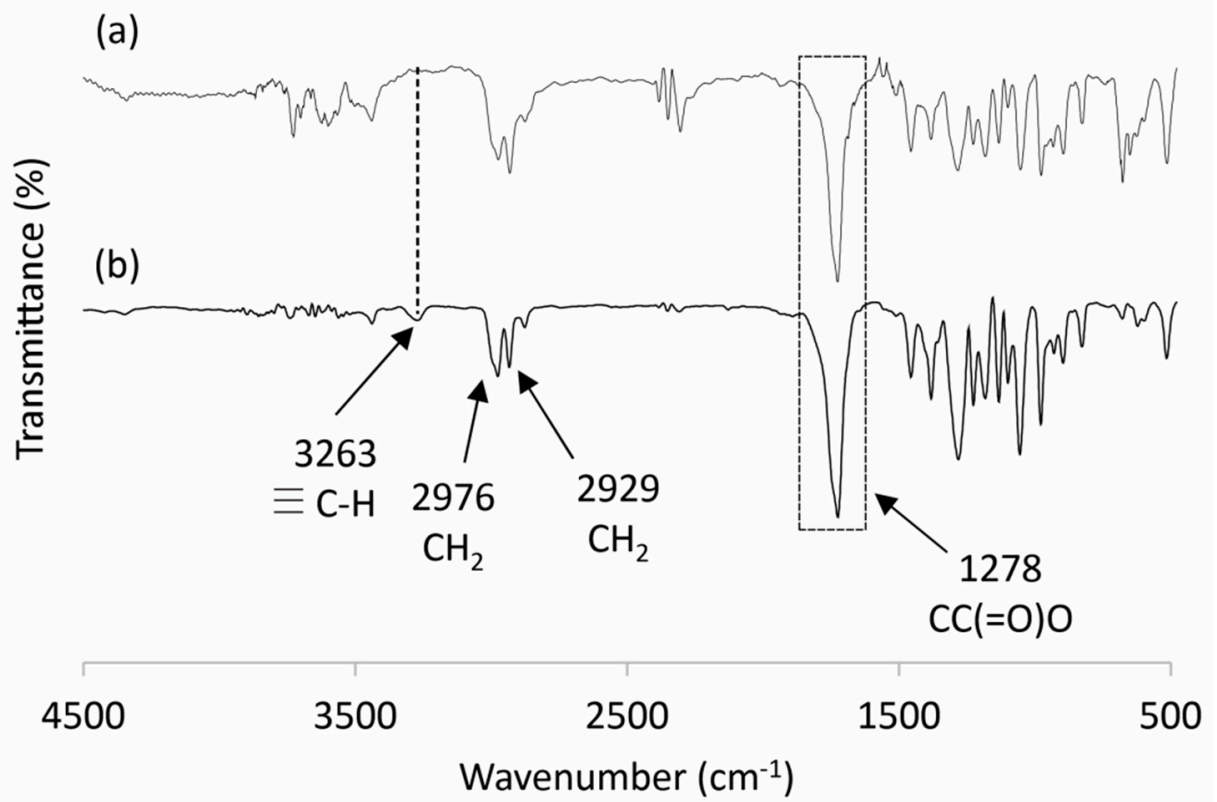

Figure 3. FTIR spectra of unmodified PHBHV (a) and PHBHV-alkyne after transesterification with propargyl alcohol (b). 


\subsection{Grafting of PHBHV-Alkyne onto PullN ${ }_{3}$ Chains via Click Chemistry}

${ }^{13} \mathrm{C}$ NMR spectra of PullN ${ }_{3}$ (Figure 4a) and Pull-g-PHBHV (Figure 4c), both compared with the ${ }^{13} \mathrm{C}$ NMR spectrum of PHBHV-alkyne (Figure $4 \mathrm{~b}$ ), showed resonances before and after the cycloaddition reaction. The resonances (ppm) at 101.1 and 98.5, from anomeric carbon in $\alpha(1 \rightarrow 4)$ - and $\alpha(1 \rightarrow 6)$-linked glucose units of PullN $_{3}$ (Figure 4a) are less evidenced in the Pull-g-PHBHV spectrum shown in Figure $4 \mathrm{c}$, and this occurs mainly because of two reasons: the overlapping of PHBHV peaks in the same region and the greater noise presented by the grafted polymer analysis signal. The analysis had to be performed in solid-state, due to the insolubility of Pull-g-PHBHV in the deuterated solvents used for this technique. However, it can be noticed the presence of a predominant peak from $\mathrm{PullN}_{3}$ at $72.2 \mathrm{ppm}$ in the copolymer spectrum (Figure 4c). Besides that, the resonance at $89.4 \mathrm{ppm}$ from the alkyne carbon of the propargyl termination of PHBHV disappeared after its grafting onto pullulan, indicating the success of the click chemistry reaction between the azide and the alkyne.

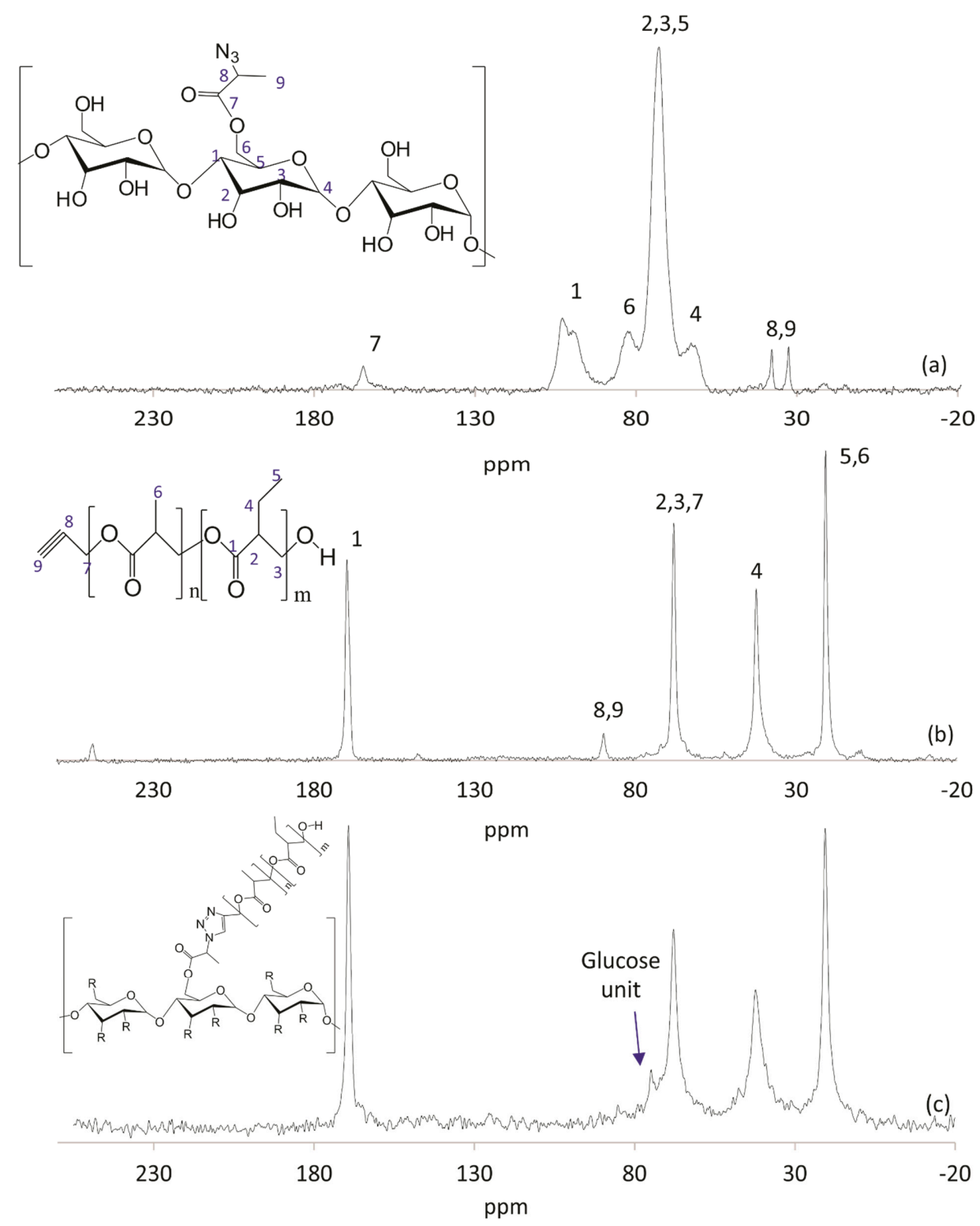

Figure 4. 110,5 MHz solid-state ${ }^{13} \mathrm{C}$ NMR spectra of PullN ${ }_{3}$ [29] (a), PHBHV-alkyne (b) and Pull-g-PHBHV (c). 
Analyzing the FTIR spectra of the azide-functionalized pullulan PullN $\mathrm{N}_{3}$ [29] (Figure 5a) and Pull-g-PHBHV (Figure 5c), both compared with the PHBHV-alkyne FTIR spectrum (Figure 5b), it can be noticed the disappearance of the characteristic stretching related to the $\mathrm{C}-\mathrm{N}_{3}$ bond at $2042 \mathrm{~cm}^{-1}$, when comparing Figure $5 \mathrm{c}$ with Figure $5 \mathrm{a}$. This fact evidences the grafting of the PHBHV copolymer onto pullulan chains via click chemistry. In addition, the appearance of stretching at $3375 \mathrm{~cm}^{-1}$ corresponding to an $-\mathrm{OH}$ bond, in Figure $5 \mathrm{c}$, characterizes the presence of the remaining pullulan hydroxyl groups in the obtained grafted copolymer. Finally, the axial stretching at $1722 \mathrm{~cm}^{-1}(-\mathrm{C}=\mathrm{O})$ observed in Figure $5 c$ is typical of carbonyl groups from PHBHV chains, as corroborated by Figure $5 b$. These results evidence the success of the click chemistry reaction.

(a)

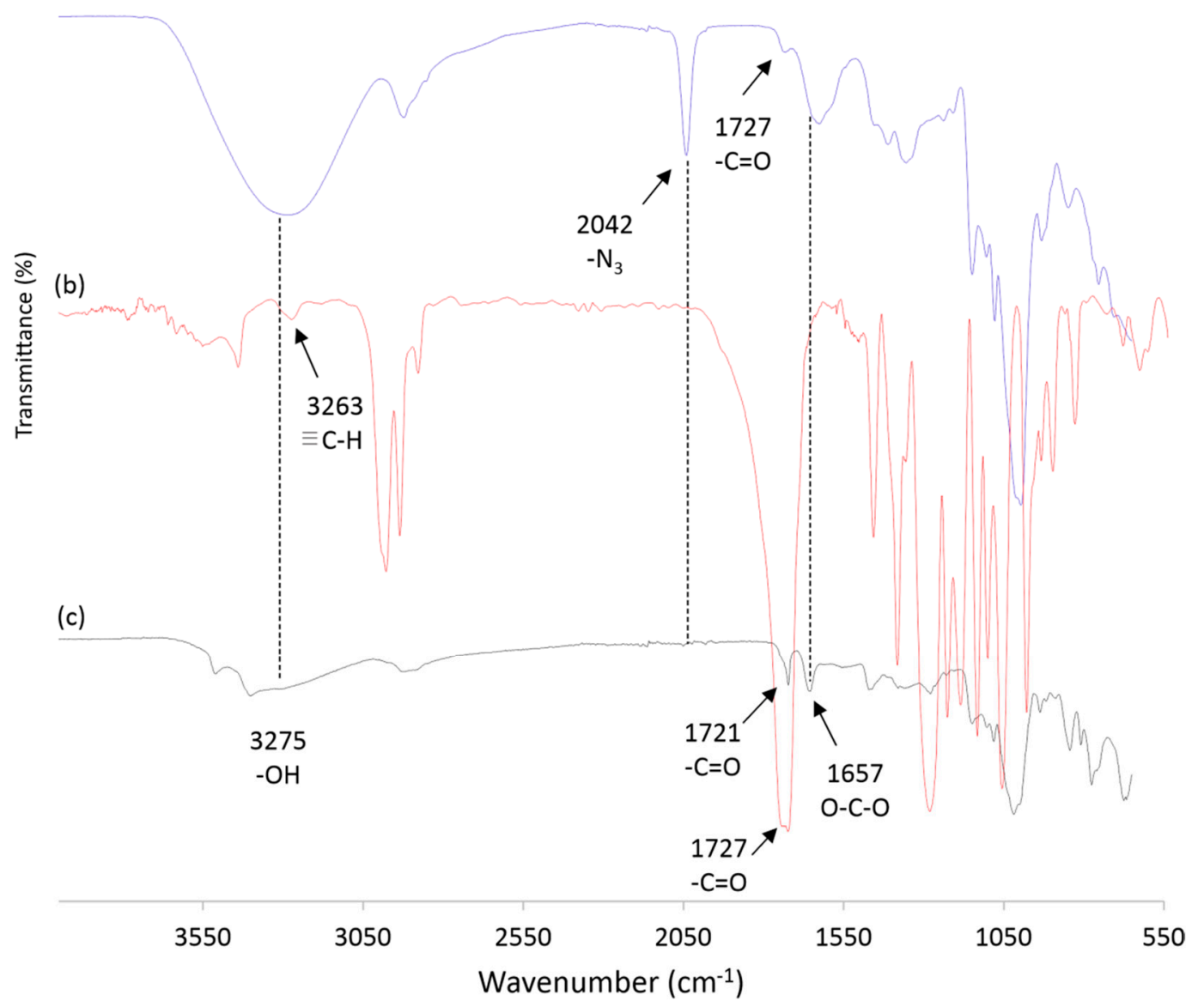

Figure 5. FTIR spectra of PullN 3 (a), PHBHV-alkyne (b) and Pull-g-PHBHV (c).

Figures 6-8, respectively, reveal the results concerning the thermal behavior (DSC), degradation (TGA) and crystallinity (DRX) of the prepared grafted copolymer Pull-g-PHBHV. DSC thermograms shown in Figure 6 reveal a different thermal behavior between the PHBHV-alkyne and grafted copolymer Pull-g-PHBHV. As previously discussed by Carvalho et al., 2020, PullN 3 showed neither clear glass transition temperature $(\mathrm{Tg})$ nor crystalline melting peak $(\mathrm{Tm})$. This occurs due to the variability of pullulans' properties which depends on the culture medium used for the production, and the tendency to retain humidity, especially for a hydrophilic polymer such as pullulan $[29,34]$. The PHBHV-alkyne thermogram revealed two melting peaks: at 122.2 and $136.8^{\circ} \mathrm{C}$, making the proximity of the values result in an overlapping of the peaks (Figure $6 \mathrm{~b}$ ). The presence of these two peaks is justified by the melting of crystals with different lamellar thicknesses or crystal structures, which occurs by a drastic temperature reduction resulting in the formation of crystals with low homogeneity [35]. The PHBHV melting-recrystallization-remelting, as well as the values found, 
are close to others previously reported in the literature $[35,36]$. When PHBHV chains were grafted onto pullulan, getting the Pull-g-PHBHV copolymer, a significant change in the melting point was observed. In addition, the decrease in the summation of the PHBHV-alkyne melting enthalpy peaks alongside the disappearance of the crystallinity peak $(T c)$ in Figure $6 \mathrm{~b}$ when compared to the value of $46.0^{\circ} \mathrm{C}$ in Figure 6a corroborate with the statement that PHBHV crystallinity was affected after its grafting onto pullulan amorphous chains.

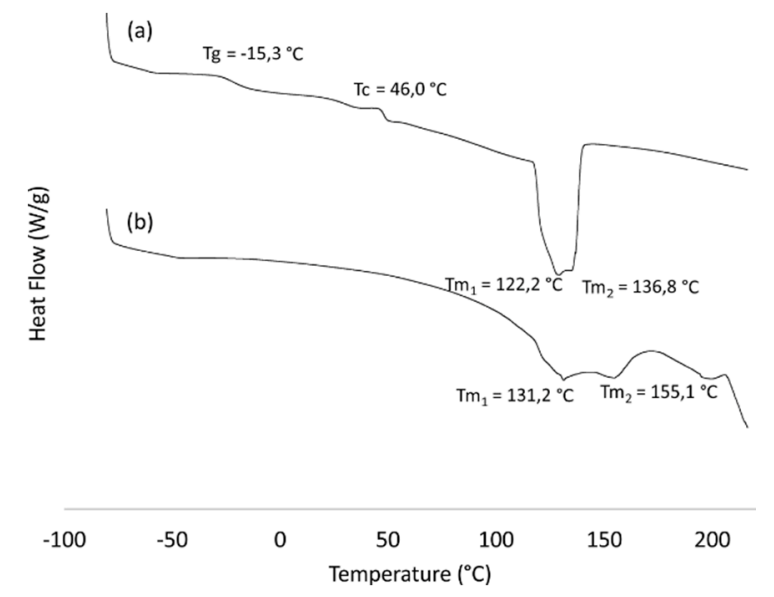

Figure 6. DSC thermograms of PHBHV-alkyne (a) and Pull-g-PHBHV (b).
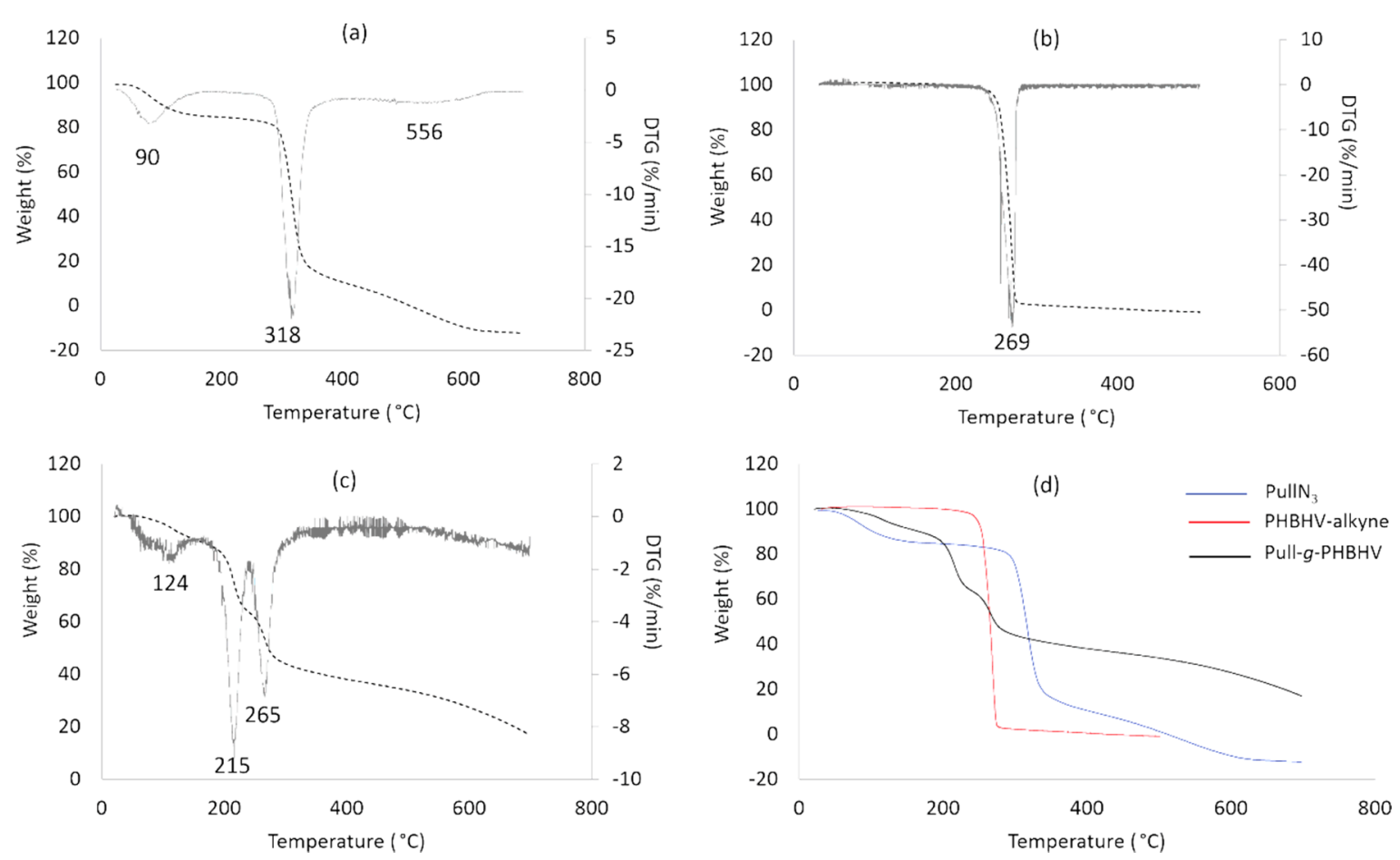

Figure 7. Thermogravimetric curves of PullN 3 (a), PHBHV-alkyne (b) and Pull-g-PHBHV (c), with the respective derivatives, as well as correlation between the thermogravimetric curves of the functionalized polymers and the grafting product $(\mathbf{d})$. 


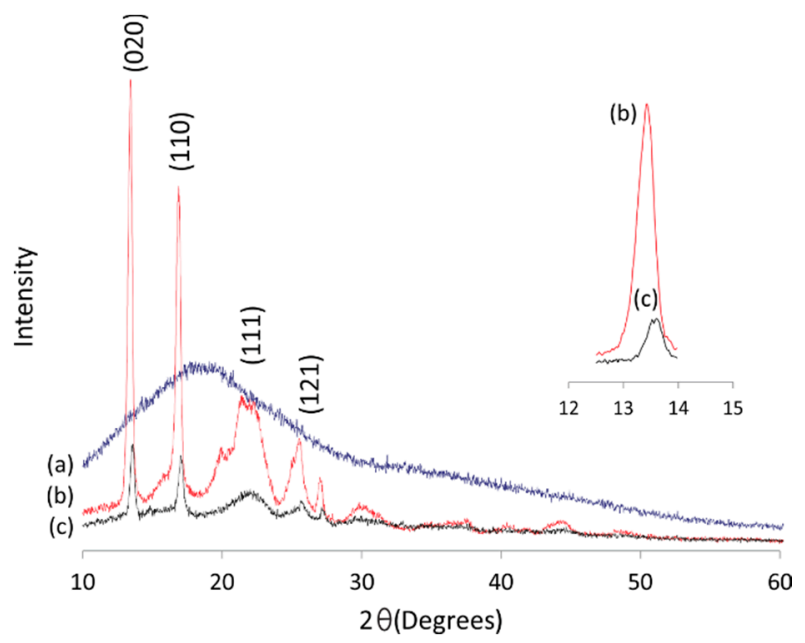

Figure 8. XRD diffractogram of PullN 3 (a) PHBHV-alkyne (b) and grafted Pull-g-PHBHV copolymer (c).

Thermogravimetric analyses of the polymers used in the click chemistry reaction, and their reaction product, enabled an evaluation of the thermal stability of the materials. The pullulan behavior shown in Figure 7a presented three stages of mass loss: (i) the first when Tmax equals $90{ }^{\circ} \mathrm{C}$ is due to vaporization of the moisture absorbed by the hydrophilic material, (ii) the second peak when Tmax equals $318^{\circ} \mathrm{C}$ is due to the disintegration of the pullulan macromolecular chains and, finally, (iii) the third when Tmax equals $556^{\circ} \mathrm{C}$ results from the degradation of the polymer by-products, that is, the saccharide rings $[18,37]$. In Figure $7 \mathrm{~b}$, the PHBHV-alkyne behavior showed a single thermal decomposition stage, at $269^{\circ} \mathrm{C}$, which mainly occurs by a nonradical random chain scission mechanism involving a six-membered ring transition state [36]. For the thermal degradation of the Pull-g-PHBHV copolymer, three degradations were observed in three stages of mass loss, at 124,215 and $265{ }^{\circ} \mathrm{C}$, respectively. Comparing all the obtained thermograms, it is clear that Pull-g-PHBHV presents lower degradation temperature values, indicating its minor thermal stability. The presence of amine groups from the 1,2,3-triazol may enhance the copolymer degradation, as the decomposition products, amines or acidic protons could increase the random chain scission reaction of polyhydroxyalcanoate [38].

The XRD analysis confirmed the partial crystallinity of the PHBHV-alkyne, showing characteristic peaks of the material, such as (020), (110), (111) and (121) (Figure 8b) [39]. However, after its grafting onto pullulan chains, whose amorphous structure is shown in the diffractogram of Figure 8a, a reduction in the crystallinity peaks of the Pull-g-PHBHV grafted copolymers could be observed (Figure 8c), compared with the starting PHBHV-alkyne. The remaining less intense crystallinity peaks in Figure $8 \mathrm{c}$ characterize the presence of the PHBHV grafted Pull-g-PHBHV structure. This intensity reduction can be attributed to the presence of pullulan in the material.

\section{Conclusions}

In this work, the polysaccharide pullulan was chemically modified by grafting poly(3-hydroxybutyrate-co-3-hydroxyvalerate) onto its backbone via click chemistry. We used previously prepared azide-functionalized pullulan and synthesized PHBHV-alkyne via a transesterification reaction. The functionalized polymers were then conjugated via CuAAC for the synthesis of Pull-g-PHBHV. The chemical structure of the grafted copolymer was characterized by ${ }^{13} \mathrm{C}$ NMR and FTIR techniques. Further analyses were conducted to demonstrate the modification in the thermal and crystallinity index of the materials, such as DSC, TGA and XRD techniques. Therefore, by the CuAAC reaction, a novel material has been developed from well-known bio-derived and biodegradable polymers, resulting in a final copolymer with interesting properties for further applications in biomedical applications, such as biodegradability and reduced crystallinity. The CuAAC methodology has the advantages of controlling both the amount and size of the polymer being grafted onto the pullulan's backbone, varying 
according to the degree of substitution obtained from the polysaccharide modification. Besides that, this copolymer synthesis method guarantees the remaining of hydroxyl groups from pullulan without further modification, keeping the polysaccharide's hydrophilic properties. Furthermore, the polymers used for the synthesis of this new graft copolymer, pullulan and PHBHV, are both biocompatible and biodegradable, making possible the development of a unique material with great potential for biomedical devices. Finally, it is important to highlight that the Pull-g-PHBHV grafted copolymer is an innovative biopolymer, carefully prepared considering its future applications in the elaboration of particles for the encapsulation of active ingredients and evaluation of controlled release systems. Therefore, Pull-g-PHBHV has good potential to be applied in the biomedical field, mainly as a drug delivery system.

Author Contributions: L.T.d.C. and M.L.d.S.P. carried out the methodology presented in this manuscript. L.T.d.C. also developed as well as the interpretation of data and writing-review and edition. R.M.d.M. contributed to the developed methodology and data curation. G.M.A. contributed with the data curation and analysis. T.M.L. and J.C.d.S. provided the resources to the methodology development. A.M.d.S. participated by providing the resources and conceptualization. S.d.F.M. contributed with writing-review and edition, funding acquisition, administration of the project and supervision. All authors have read and agreed to the published version of the manuscript.

Funding: This research was funded by Coordination for the Improvement of Higher Education Personnel (CAPES) and São Paulo Research Foundation (FAPESP), grant number [2019/04269-0 and 2019/12940-4], and the APC was funded by São Paulo Research Foundation (FAPESP), grant number [2019/04269-0 and 2020/10616-2].

Acknowledgments: The authors acknowledge Eduardo Ribeiro de Azevedo for assistance with ${ }^{13} \mathrm{C}$ NMR analyses.

Conflicts of Interest: The authors declare no conflict of interest.

\section{References}

1. Luef, K.P.; Stelzer, F.; Wiesbrock, F. Poly(hydroxy alkanoate)s in medical applications. Chem. Biochem. Eng. Q. 2015, 29, 287-297.

2. Li, Z.; Pan, T.; Wu, Y.; Kang, W.; Liu, Y. Preparation and characterization of long-term stable pullulan nanofibers via in situ cross-linking electrospinning. Adsorpt. Sci. Technol. 2018, 37, 401-411. [CrossRef]

3. Ulery, B.D.; Nair, L.S.; Laurencin, C.T. Biomedical Applications of Biodegradable Polymers. J. Polym. Sci. B Polym. Phys. 2011, 49, 832-864. [CrossRef] [PubMed]

4. Farris, S.; Introzzi, L.; Fuentes-Alventosa, J.M.; Santo, N.; Rocca, R.; Piergiovanni, L. Self-Assembled Pullulan-Silica Oxygen Barrier Hybrid Coatings for Food Packaging Applications. Agric. Food Chem. 2012, 60, 782-790. [CrossRef] [PubMed]

5. Meng, L.; Xie, F.; Zhang, B.; Wang, D.K.; Yu, L. Natural Biopolymer Alloys with Superior Mechanical Properties. ACS Sustain. Chem. Eng. 2018, 7, 2792-2802. [CrossRef]

6. Meng, X.; Edgar, K.J. "Click" reactions in polysaccharide modification. Prog. Polym. Sci. 2016, 53, 52-85. [CrossRef]

7. Pilon, L.; Kelly, C. Modification of poly(3-hydroxybutyrate-co-3-hydroxyvalerate) properties by reactive blending with a monoterpene derivative. J. Appl. Polym. Sci. 2015, 133, 42588. [CrossRef]

8. Singh, R.S.; Kaur, N.; Rana, V.; Kennedy, J.F. Pullulan: A novel molecule for biomedical applications. Carbohyd. Polym. 2017, 171, 102-121. [CrossRef]

9. Hasuda, H.; Kwon, O.H.; Kang, I.-K.; Ito, Y. Synthesis of photoreactive pullulan for surface modification. Biomaterials 2005, 26, 2401-2406. [CrossRef]

10. Farris, S.; Unalan, I.U.; Introzzi, L.; Fuentes-Alventosa, J.M.; Cozzolino, C.A. Pullulan-based films and coatings for food packaging: Present applications, emerging opportunities, and future challenges. J. Appl. Polym. Sci. 2014, 131, 40539. [CrossRef]

11. Kachhawa, D.K.; Bhattacharjee, P.; Singhal, R.S. Studies on downstream processing of pullulan. Carbohyd. Polym. 2013, 52, 25-28. [CrossRef]

12. Ganeshkumar, M.; Ponrasu, T.; Subamekala, M.K.; Janani, M.; Suguna, L. Curcumin loaded on pullulan acetate nanoparticles protects the liver from damage induced by DEN. R. Soc. Chem. 2016, 6, 5599-5610. [CrossRef] 
13. Singh, R.S.; Kaur, N.; Kennedy, J.F. Pullulan and pullulan derivatives as promising biomolecules for drug and gene targeting. Carbohyd. Polym. 2015, 123, 190-207. [CrossRef]

14. Tabasum, S.; Noreen, A.; Maqsood, M.F.; Umar, H.; Akram, N.; Nazli, Z.; Chatha, S.A.S.; Zia, K.M. A review on versatile applications of blends and composites of pullulan with natural and synthetic polymers. Int. J. Biol. Macromol. 2018, 120, 603-632. [CrossRef] [PubMed]

15. Guo, H.; Liu, Y.; Wang, Y.; Wu, J.; Yang, X.; Li, R.; Wang, Y.; Zhang, N. pH-sensitive pullulan-based nanoparticle carrier for adriamycin to overcome drug-resistance of cancer cells. Carbohyd. Polym. 2014, 111, 908-917. [CrossRef]

16. Bontempo, D.; Masci, G.; De Leonardis, P.; Mannina, L.; Capitani, D.; Crescenzi, V. Versatile Grafting of Polysaccharides in Homogeneous Mild Conditions by Using Atom Transfer Radical Polymerization. Biomacromolecules 2006, 7, 2154-2161. [CrossRef]

17. Spatareanu, A.; Bercea, M.; Budtova, T.; Harabagiu, V.; Sacarescu, L.; Coseri, S. Synthesis, characterization and solution behaviour of oxidized pullulan. Carbohyd. Polym. 2014, 111, 63-71. [CrossRef]

18. Constantin, M.; Mihalcea, I.; Oanea, I.; Harabagiu, V.; Fundueanu, G. Studies on graft copolymerization of 3-acrylamidopropyl trimethylammonium chloride on pullulan. Carbohyd. Polym. 2011, 84, 926-932. [CrossRef]

19. Wang, L.; Shen, J.; Men, Y.; Wu, Y.; Peng, Q.; Wang, X.; Yang, R.; Mahmood, K.; Liu, Z. Corn starch-based graft copolymers prepared via ATRP at the molecular level. Polym. Chem. 2015, 6, 3480-3488. [CrossRef]

20. Hezarkhani, M.; Yilmaz, E. Pullulan modification via poly(N-vinylimidazole) grafting. Int. J. Biol. Macromol. 2019, 15, 149-156. [CrossRef]

21. Yang, X.; Shia, X.; D’arcy, R.; Tirelli, N.; Zhaia, G. Amphiphilic polysaccharides as building blocks for self-assembled nanosystems: Molecular design and application in cancer and inflammatory diseases. J. Control. Release 2018, 272, 114-144. [CrossRef] [PubMed]

22. Bajpai, A.K.; Shukla, S.K.; Bhanu, S.; Kankane, S. Responsive Polymers in Controlled Drug Delivery. Prog. Polym. Sci. 2008, 33, 1088-1118. [CrossRef]

23. Vardhan, H.; Mittal, P.; Adena, S.K.R.; Upadhyay, M.; Mishra, B. Long-circulating polyhydroxybutyrate-co-hydroxyvalerate nanoparticles for tumor targeted docetaxel delivery: Formulation, optimization and in vitro characterization. Eur. J. Pharm. Sci. 2017, 99, 85-94. [CrossRef] [PubMed]

24. Radu, I.-C.; Hudita, A.; Zaharia, C.; Stanescu, P.O.; Vasile, E.; Iovu, H.; Stan, M.; Ginghina, O.; Galateanu, B.; Costache, M.; et al. Poly(HydroxyButyrate-co-HydroxyValerate) (PHBHV) Nanocarriers for Silymarin Release as Adjuvant Therapy in Colo-rectal Cancer. Front. Pharmacol. 2017, 8, 508. [CrossRef]

25. Gracida, J.; Alba, J.; Cardoso, J.; Perez-Guevara, P. Studies of biodegradation of binary blends of poly(3-hydroxybutyrate-co-3-hydroxyvalerate) (PHBHV) with poly(2-hydroxyethylmetacrilate) (PHEMA). Polym. Degrad. Stabil. 2004, 83, 247-253. [CrossRef]

26. Montoro, S.R.; Tebaldi, M.L.; Alves, G.M.; Barboza, J.C.D.S. Redução da Massa Molecular e Funcionalização do Poli(3-Hidroxibutirato-co-3-Hidroxivalerato) (PHBHV) Via Hidrólise Ácida e Transesterificação com Glicóis. Polímeros 2011, 21, 182-187. [CrossRef]

27. Sadik, T.; Massardier, V.; Becquart, F.; Taha, M. Synthesis and characterizations of poly(ethylene-co-vinylalcohol)-grafted-poly(3-hydroxybutyrate-co-hydroxyvalerate) copolymers. Polymers 2012, 53, 4585-4594. [CrossRef]

28. Radu, I.-C.; Hudita, A.; Zaharia, C.; Galateanu, B.; Iovu, H.; Tanasa, E.; Nitu, S.G.; Ginghina, O.; Negrei, C.; Tsatsakis, A.; et al. Poly(3-hydroxybutyrate-CO-3-hydroxyvalerate) PHBHV biocompatible nanocarriers for 5-FU delivery targeting colorectal câncer. Drug Deliv. 2019, 26, 318-327. [CrossRef]

29. Carvalho, L.T.; Moraes, R.M.; Alves, G.M.; Lacerda, T.M.; Santos, J.C.; Santos, A.M.; Medeiros, S.F. Synthesis of Amphiphilic Pullulan-Graft-Poly(E-Caprolactone) via Click Chemistry. Int. J. Biol. Macromol. 2020, 145, 701-711. [CrossRef]

30. Lemechko, P.; Renard, E.; Voleta, G.; Colin, C.S.; Guezenne, J.; Langlois, V. Functionalized oligoesters from poly(3-hydroxyalkanoate)s containing reactive end group for click chemistry: Application to novel copolymer synthesis with poly(2-methyl-2-oxazoline). React. Funct. Polym. 2012, 72, 160-167. [CrossRef]

31. Lu, C.; Zhong, W. Synthesis of Propargyl-Terminated Heterobifunctional Poly(ethylene glycol). Polymers 2010, 2, 407-417. [CrossRef]

32. Ali, M.W.; Gao, Y.; Siddiq, M.; Ye, X. A Novel Initiator Containing Alkyne Group for the Polymerization of 2-Ethyl-2-oxazoline. Chin. J. Chem. Phys. 2018, 31, 77-84. [CrossRef] 
33. Lemechko, P.; Renard, E.; Guezennec, J.; Simon-Colin, C.; Langlois, V. Synthesis of dextran-graft-PHBHV amphiphilic copolymer using click chemistry approach. React. Funct. Polym. 2012, 72, 487-494. [CrossRef]

34. Teramoto, N.; Shibata, M. Synthesis and properties of pullulan acetate. Thermal properties, biodegradability, and a semi-clear gel formation in organic solvents. Carbohydr. Polym. 2006, 63, 476-481. [CrossRef]

35. Montanheiro TL do, A.; Passadora, F.R.; Oliveira MP, d.e.; Durán, N.; Lemes, A.P. Preparation and Characterization of Maleic Anhydride Grafted Poly (Hydroxybutirate-CO-Hydroxyvalerate)—PHBV-g-MA. Mater. Res. 2016, 19, 229-235. [CrossRef]

36. Liu, Q.-S.; Zhu, M.-F.; Wu, W.-H.; Qin, Z.-Y. Reducing the formation of six-membered ring ester during thermal degradation of biodegradable PHBV to enhance its thermal stability. Polym. Degrad. Stabil. 2009, 94, 18-24. [CrossRef]

37. Islam, M.S.; Yeum, J.H.; Das, A.K. Synthesis of poly(vinyl acetate-methyl methacrylate) copolymer microspheres using suspension polymerization. J. Colloid Interface Sci. 2012, 368, 400-405. [CrossRef]

38. Thiré, R.M.D.S.; Arruda, L.C.; Barreto, L.S. Morphology and Thermal Properties of Poly(3-hydroxybutyrate-co-3-hydroxyvalerate)/Attapulgite Nanocomposites. Mater. Res. 2011, 14, 340-344.

39. Barcelosa, M.V.; Neto, G.R.D.A.; Almeida, F.M.; Rodríguez, R.J.S.; Gomez, J.G.C. Mechanical Properties of P(HB-HV) Nanocomposites Reinforced by Nanodiamonds. Mater. Res. Ibero Am. J. 2017, 20, 1-7. [CrossRef]

(C) 2020 by the authors. Licensee MDPI, Basel, Switzerland. This article is an open access article distributed under the terms and conditions of the Creative Commons Attribution (CC BY) license (http://creativecommons.org/licenses/by/4.0/). 